\title{
Erratum
}

\section{Shock response of the commercial high explosive Detasheet}

B.W. Assay ${ }^{1}$, J.B. Ramsay ${ }^{1}$, M.U. Anderson ${ }^{2}$, R.A. Graham ${ }^{2}$

1 Los Alamos National Laboratory, Los Alamos, New Mexico, USA

2 Sandia National Laboratories, Albuquerque, New Mexico, USA

Shock Waves 3, 267-271 (1994)

Unfortunately Table 1 was accidentally omitted from this paper. It is therefore printed now below:

Table 1. Summary of impact experiment measurements

\begin{tabular}{lrrrrrrrr} 
Exp.-no. & $\begin{array}{r}\text { Impact } \\
\text { velocity } \\
(\mathrm{km} / \mathrm{s})^{\mathrm{b}}\end{array}$ & $\begin{array}{c}\text { Shock- } \\
\text { velocity } \\
(\mathrm{km} / \mathrm{s})^{\mathrm{c}}\end{array}$ & \multicolumn{2}{c}{$\begin{array}{c}\text { Particle } \\
\text { velocity } \\
(\mathrm{km} / \mathrm{s})\end{array}$} & & \multicolumn{3}{c}{$\begin{array}{c}\text { Impact surface } \\
\text { stress } \\
(\mathrm{GPa})\end{array}$} \\
\hline & & & $\mathrm{A}^{\mathrm{d}}$ & $\mathrm{B}^{\mathrm{e}}$ & $\mathrm{C}^{\mathrm{f}}$ & $\mathrm{A}^{\mathrm{d}}$ & $\mathrm{B}^{\mathrm{g}}$ & Equil. $^{\mathrm{h}}$ \\
$2377-8$ & 0.126 & 2.027 & 0.107 & 0.10 & 0.11 & 0.321 & 0.31 & 0.35 \\
$2382-3$ & 0.132 & 2.069 & 0.112 & 0.10 & 0.11 & 0.342 & 0.30 & 0.32 \\
$2383-3$ & 0.231 & 2.304 & 0.192 & 0.19 & 0.20 & 0.655 & 0.63 & 0.68 \\
$2379-8$ & 0.238 & 2.286 & 0.198 & 0.18 & 0.20 & 0.671 & 0.65 & 0.76 \\
$2374-8$ & 0.381 & 2.566 & 0.312 & - & - & 1.184 & - & - \\
$2384-3$ & 0.390 & 2.587 & 0.319 & - & - & 1.222 & - & - \\
$2378-3$ & 0.529 & 2.840 & 0.425 & 0.45 & 0.42 & 1.787 & 1.9 & 2.1 \\
$2376-3$ & 0.730 & 3.175 & 0.575 & 0.60 & 0.57 & 2.701 & 2.8 & 3.2 \\
\hline
\end{tabular}

${ }^{a}$ Experiment number-nominal sample thickness in millimeters

${ }^{b}$ Projectile impact velocity measurement, $0.1 \%$ accuracy

${ }^{c}$ Average shock velocity measurement through sample, $0.15 \%$ accuracy for $8 \mathrm{~mm}$ sample, $0.4 \%$ accuracy for $3 \mathrm{~mm}$ sample

${ }^{\mathrm{d}}$ Method A calculation using intersection of $\mathrm{z}-\mathrm{SiO}_{2}$ Hugoniot and Detasheet $\rho_{0} \mathrm{U}_{\mathrm{s}}$ slope

${ }^{\text {e }}$ Method $B$ calculation using PVDF instantaneous stress divided by Detasheet $\rho_{0} \mathrm{U}_{\mathrm{S}}$

${ }^{\mathrm{f}}$ Method $\mathrm{C}$ calculation using intersection of $\mathrm{z}-\mathrm{SiO}_{2}$ Hugoniot and PVDF impact stress measurement ${ }^{\mathrm{g}}$

gPVDF instantaneous impact stress measurement

${ }^{\mathrm{h}}$ PVDF equilibrium impact stress measurement 